\title{
Social Constructivism: A New Paradigm in Teaching and Learning Environment
}

\author{
Amna Saleem \\ Ph.D. Scholar (CA) \\ Department of Education \\ International Islamic University Islamabad \\ Huma Kausar \\ Ph.D. Scholar \\ Department of Education \\ International Islamic University Islamabad \\ Farah Deeba \\ Assistant Professor \\ Department of Education \\ Bahauddin Zakariya University, Multan
}

\begin{abstract}
:
This study aimed to examine social constructivism as a learning theory and its implications for teaching methods, student motivation, and the whole teaching/learning process. Social constructivism is a collaborative learning approach that emphasizes student involvement, discussion, and knowledge exchange. According to social constructionism, we never know universally true or untrue, good or bad, right or wrong. Each of us invents our universe based on our impressions of reality. Language, communication, and speech are social constructions in social constructionism and occupy a pivotal position in the interactive process we comprehend the world and ourselves. It is the teacher's responsibility to use learner-centered and collaborative teaching approaches. The underlying factor is that students collaborate in groups to share ideas, solve problems, or create something new to add to their existing knowledge. This learning theory stresses active interaction among learners, the teacher, and other components of the teaching-learning process rather than teacher monotony in the classroom. It also exhibits pupils to remember facts they uncover and construct themselves rather than those the teacher tells them.
\end{abstract}

Keywords: Constructivism, Social constructivism, Implications, Learning, Teaching 


\section{Introduction}

Learning takes place in a variety of methods and at a variety of degrees. This serves as the foundation for a variety of learning theories. Learning theories describe how students process, absorb, and retain Knowledge during the teaching/learning experience. The three broad learning theories that have endured throughout history are behavioral, cognitive, and constructivist learning theories. In behavioral learning theory, the student is primarily passive and reliant on the teacher since the learner is viewed as an empty vessel ready to be filled with Knowledge and information. This theory flourishes in situations where rote Learning, repetition, and recall are required. Individual students' mental processes emphasize the cognitive theory related to thinking, concept generation, reasoning, and problem-solving. Following that, the constructivism theory asserts that Learning occurs when learners actively construct or create basic information by themselves, as they do through inquiry and discovery. While briefly reviewing the idea of constructivism, our primary focus will be on social constructivism, which emphasizes the importance of contact, collaboration, and group work to achieve effective learning outcomes (Nawaz, 2012).

The definition of constructivism varies depending on one's perspective and organization. There are philosophical meanings of constructivism in educational contexts and personal constructivism as defined by Piaget, 1967; social constructivism as defined by Vygotsky, 1978; radical constructivism as supported by Von Glasersfeld, 1995. Constructivist epistemologies and educational constructivism as described by Mathews, 1998. Because they appear to be the most advantageous to include into current educational practices, social constructivism and educational constructivism, which incorporates theories of Learning and pedagogy, have had the most significant impact on instruction and curriculum design. As a result, it can be argued that most scholars and writers have studied various constructivist theories (Mathieson, 2012).

The interdependence of social and individual processes in the coconstruction of Knowledge is the focus of social constructivist perspectives; after reviewing the momentum for understanding the influence of social and cultural factors on cognition, methods for accounting for learning from this perception are identified. The Piagetian and Vygotskian accounts were used to create the main drawing. The empirical research examined demonstrates the use of institutional analysis to explore Education and schooling as a cultural process, interpersonal analysis to investigate how communication strengthens cognition and 
Learning, and discursive analysis to examine and manipulate the prototypes and opportunities in instructional conversation (Kiraly,2014).

\section{Objectives:}

-To explain the concept, characteristics and significance social constructivism.

-To identify the influence of social constructivism on teaching learning process.

-To elaborate model of social constructivism in teaching learning process.

\section{Methodology}

The research is purely conceptual. The secondary data has been gathered from various sources, including websites, eBooks, and periodicals.

\section{Theory of Constructivism}

In 1966, Jerome Bruner proposed constructivism. The notion suggests that people learn about the world through experiencing it and reflecting on it. This philosophy is founded on cognitive theory concepts, hence cognitive constructivism (Olorode and Jimoh, 2016).

Kussmaul \& Pirmann (2021) states that when we receive new Knowledge, we either reconcile it with our prior beliefs or dismiss it as unimportant. In any event, we create our knowledge. To do so, we must ask questions, investigate, and evaluate. This explains that learners develop Knowledge as they try to make sense of their experiences. People actively create new information when they interact with their environment (Kanno,2018).

Constructivist learning encourages students to apply practical methods to gain Knowledge, reflect, and discuss their work in the classroom. The philosophy discourages memorizing others' conceptions and definitions and encourages learners to discover their own. Children can develop their straightforward explanation instead of memorizing the age-extended definition of a phrase after investigating its placement in a sentence. They do this sometimes with their coworkers. Now to the social side of constructivism (Fleury \& Garrison,2014).

Constructivism is a theory about how people learn based on scientific observation. People create their understanding, it argues. World knowledge gained via experience and reflection. When we learn anything 
new, we must reconcile it with our prior Knowledge and experience, possibly modifying our beliefs or dismissing it as irrelevant. In any event, we are active knowledge creators. To do so, we must ask questions, investigate, and evaluate. In the classroom, constructivism can lead to a variety of instructional methods (Kutay, Howard-Wagner, Riley \& Mooney, 2012).

It generally involves encouraging students to employ active methods (experiments, real-world problem solving) to gain Knowledge and discuss their findings. The teacher guides the exercise to confront and build on the students' preexisting conceptions (Amineh \& Asl,2015).

\section{Social Constructivism}

Social constructivism is a learning theory proposed by Lev Vygotsky in 1968. Language and culture, in this view, are frameworks through which humans experience, communicate, and comprehend reality. Language and culture, according to Vygotsky, influence people's intellectual growth and perception of their environment. Language transmission results in learning concepts being interpreted and assimilated through experience and cultural context. Knowledge is socially produced and co-constructed since it requires a community of people who share a language and culture. The social constructivist views knowledge as something children have in partnership with other students, teachers, and peers. This style of cognitive constructivism promotes collaborative Learning, either with a facilitator or with other students (Mohammed \& Kinyo,2020).

Kennedy (2014) According to social constructivism, children's understanding is influenced by adaptive encounters with the physical world and interpersonal exchanges about a cultural, meaningful, and relevant reality.

Taylor (2018) defines potential growth (academic achievement) as the level of development a learner can attain with the help of teachers or peers. He sees learning as a social activity that involves peers, family members, casual acquaintances, and historical figures. According to Social Constructivism, dialogue, collaboration, and information use are crucial components of Learning and strategies for achieving learning goals.

Vygotsky believed that social interaction is necessary for lifelong personality development and that social Learning adds to cognitive growth. In other words, learners may complete any activity (regardless of difficulty) with the help of an adult or peer collaboration. This approach helps students collaborate with their teacher and classmates to build 
Knowledge and comprehension by establishing a firm basis (Aljohani,2017).

According to Fleury \& Garrison (2014), the social production of Knowledge occurs in various circumstances and levels of sophistication. For example, in an educational or training institution, a social media forum, a religious context, or a market environment. Interacting with others and their physical and immaterial settings helps pupils gain insight and experience to aid them as adults.

Social constructivism is a teaching technique that emphasizes student participation, discussion, and sharing. This teaching technique allows for several groupings and interactive tactics. Whole-class conversations, small-group discussions, and student involvement on specific topics (for example, in pairs). Students share ideas and brainstorm to find cause-andeffect links, answers to problems, or just something new to add to their existing Knowledge (Al-Qaysi, Mohamad-Nordin \& Al-Emran, 2021).

\section{Characteristics of Social Constructivism}

The concept of how social constructivism interprets the Learning and learning communities can be accomplished by knowing the facts that express how social constructivism sees Learning and learning communities. There are the five following primary sections that emphasize the overview of social constructivism

\section{Learners construct their knowledge}

Students, trainees, and others should develop their knowledge since their minds create new Knowledge and information. Reasoning, accepted wisdom, and judgment is all involved. New concepts and ideas can't be grasped until they're linked to previous ones. As Dewey said, Education is an active and productive process rather than just telling and listening passively. Instead of being absorbed in their current form, information, ideas, and Knowledge obtained from others are transformed and appraised.

\section{Knowledge is acquired through experience}

Educators impart theoretical and conceptual Knowledge to learners, while an individual receives Knowledge from his life experiences. In contrast, learners acquire academic Knowledge by utilizing their prior experiences to enrich their learning experiences, understanding and interpreting the significance of acquired Knowledge, especially the adult learners. So, 
Learning occurs as a result of learners' real-life experiences. Similarly, when instructors are transferring Knowledge to their students about a particular concept or theory, i.e., the idea of pollution, types of pollution, and causes and effects of pollution, the instructors may even give examples and causes of pollution from their own experiences and life incidents, if a teacher' health is affected by pollution so he may explain how air pollution is harmful to an individual by using the examples from their own experiences to explain the detrimental effects of air pollution on health.

\section{Learning is a social activity}

Social, interpersonal connection, and communication with community members all help instill Learning in people. Cultures, language, and other social norms and beliefs all contribute to people learning. Learning is a social activity such as being an active or social individual of society. A person knows multiple things and becomes familiar with various areas, objects, and articles. It is challenging to become aware of multiple areas and subjects by remaining isolated and not being social. The learners benefit from emotional and robust support from the community, which allows them to face challenges and take control of their Learning.

\section{All parts of a learner are interconnected}

Social interaction is vital for acquiring Knowledge, but attitudes, emotions, values, and behaviors are equally important from social constructivism. The human actions and body link, i.e., Knowledge, pleasure, ethics, and aesthetics. Students in educational institutions require a wide range of possibilities and reinforcement to develop their entire way of life and critically apply it to acquire academic Learning. Knowledge and popular culture have a relationship; both are utilized to provide insight, instruction, and enhancement to one's life.

\section{Inclusive and equitable learning communities}

Individuals' needs for Knowledge, information, and awareness, and acknowledgment of the social character of Learning point to learning communities that are inclusive and fair. Dewey and Piaget emphasized learning community inclusiveness and aid learners in developing a feeling of dignity and their ideas, thoughts, conceptions, impressions, opinions, viewpoints, and way of life. Institutions should respect one another's uniqueness and offer a foundation for people to construct reality from their unique perspectives (Rannikmäe, Holbrook, \& Soobard, 2020). 
The following are some of the features of social constructivism: learners construct Knowledge, Knowledge is founded on experience, Learning is social, all elements of a person are connected, and learning communities should be inclusive and egalitarian. According to the social constructivist perspectives, Learning is a self-motivated process that fascinates learners' prior Knowledge into learning new ideas and concepts, building on suppositions and removing cognitive conflicts. At the same time, instructors can plan curriculum and instructional pedagogies beyond the past Knowledge to significant substantial Knowledge (Singh \& Yaduvanshi ,2015).

Individuals acquire Knowledge and awareness about serval concepts, methods, understandings, experiences, and wisdom by enrolling in educational programs, training institutions, group discussion forums, participating in teamwork, etc (Amineh \& Asl, 2015).

Teachers encourage students to become more inventive through social constructivist principles. Teachers use raw data, primary sources, and cognitive terminology to deliver training and instruction to students, and students' responses are used to inform the teaching and learning process. Finally, it can be stated that many writers have focused on the theory of social constructivism, which includes most of the aspects that aid in encouraging learners to acquire Education and understanding; an individual learns to connect his values, norms, attitudes, behavioral traits, actions, and emotions (Kutay, Howard-Wagner, Riley \& Mooney,2012)

\section{Social Constructivist Five E's Instructional Model}

Several social constructivist learning models can be utilized to design a conducive learning environment for learners. Singh \& Yaduvanshi (2015) proposed an instructional model based upon Piaget's work in the early 1960s for instructions. This model depicted the systematic application of psychology to teaching science content. This model is very convenient to implement in the classroom. The $5 \mathrm{E}$ 's instructional model consists of the five following phases: engage, explore, explain, elaborate, and evaluate to develop a better understanding of scientific and technological Knowledge and skills (Bybee, 2009). Each phase of this model has a specific function and contribution to fostering the classroom's constructivist approach (Omotayo, \& Adeleke, 2017). Following is the description of the five phases of this instructional model. 


\section{Engagement}

This model phase actively engages learners in classroom learning activities by making connections between the past and present learning experiences. These connections can be conceptual, procedural, or behavioral. The instructor introduces a situation, and learners have to identify the solution of the problem, while the role of the instructor here is to identify the instructional task and present a situation to learners (Omotayo, \& Adeleke, 2017).

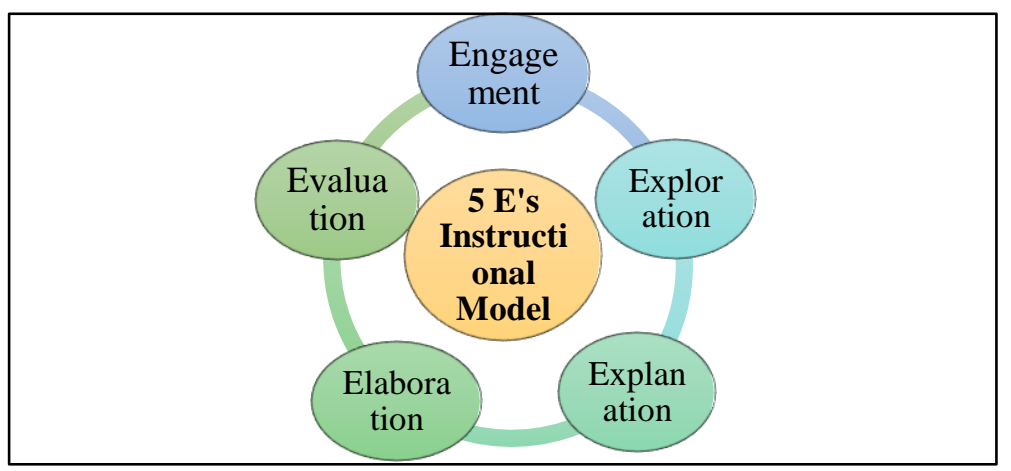

\section{Exploration}

The instructor designs the learning activities and situations to provide common and concrete learning experiences in this phase. The primary purpose of exploration tasks is to establish learning experiences that can be utilized for later teaching and Learning, such as introducing the new topic or concepts, discussion, and skills learning. This phase mentally and physically involves the learners recognizing the unique situation, procedures, skills, and building relationships. At the same time, the instructor facilitates and provides coaching to their learners in learning tasks (Sharma \& Bansal, 2017).

\section{Explanation}

The explanation phase furnishes the instructor and learners relative to learning experiences to clarify the concepts, procedures, and skills. The explanation phase is known as teacher-directed or direct instruction that helps explain the concepts and skills that the learners have already explored in the previous phase. The most important feature of this phase 
is to present the concept concisely, clearly, directly and move to the next phase (Bybee, 2009).

\section{Elaboration}

Once the learners have explored and explained, they should have allowed and provided further experiences to extend, implement, and elaborate the concepts and skills. Moreover, the elaboration tasks provide the learning experiences that contribute to Learning (Aljohani,2017).

\section{Evaluation}

This phase provides feedback to the learners on the adequacy of their explanations and capabilities. Instructors can conduct the formal evaluation after their elaboration phase. This is the last phase of the 5 E's which encourages learners to assess their understanding and abilities and lets teachers evaluate students' understanding of key concepts and skill development (Singh \& Yaduvanshi, 2015).

\section{Implications of Social Constructivism on Teaching Methods}

Teaching methods are the underlying art and science that informs management and strategies used in the classroom to teach pupils. Dorgu (2015) defines teaching method as to how a teacher presents their subject matter to students to encourage Learning. This method is used to teach the student-specific subject matter. Aljohani (2017) defines teaching technique as the concepts and strategies used by teachers to help students learn. These definitions show that there exist concepts and instructional methods that maximize student learning. These ideas and behaviors are based on learning theories like social constructivism. According to social constructivism, Knowledge is derived from social interaction and is something that a group of people can share rather than own.

Kelly (2012) advocates employing social constructivism in the classroom with these instructional strategies. Examples of instructional strategies include case studies, research projects, problem-based Learning, brainstorming, group work, guided discovery learning, and simulations. The teacher can divide the class into groups or pairs and then lead the groups or teams through the process of discovery and learning by prompting, questioning, and directing them towards the desired outcomes. The following are two broad groups of social constructivism teaching approaches: There's action, group work, and discussion. Listed below are a few strategies to consider: 
Omwirhiren (2015) describes a discussion technique as using directed engagement to increase student learning. Jegede (2010) argues it promotes Learning by allowing students to strengthen communication and mental abilities, including critical thinking, reflection, and evaluating opposing viewpoints. The teacher is more of a facilitator than a lecturer in this method. The teacher takes pupils through the process of self-discovery using educated dialogue. Collaborative Learning occurs when students and teachers work together on a topic. Discussions in small groups or as a class can help achieve this. The teacher facilitates the discussion, but all pupils are free to express themselves. Rules are set upfront to prevent chaos. This method of teaching increases student attention, remember, and participation in the course. It promotes democratic thinking among students by encouraging free debate and mutual understanding. This helps children develop reflective thinking abilities, which will help them analyze and comprehend challenges better. These activities help students improve their communication skills and tolerance by accepting and respecting others' perspectives even if they disagree. It is possible to teach and learn through discussion methods such as debate, group work, and other socially engaged approaches. They encourage research, oral and written communication abilities, and the ability to evaluate others' views.

Small groups of students work together to achieve a common goal. Students assume a role within the group, official or informal, and positions frequently change. Reflection and reasoning are essential in learning design. Identifying what they already know, what they need to learn, and how and where to get new information may help them solve their challenge. The teacher's role is to support, guide, and monitor pupils' progress during the learning process. The teacher's goal is to develop pupils' self-confidence while also widening their material understanding. This teaching and learning technique represents a paradigm shift from traditional lecture-based teaching and learning methodologies. Group work includes, for example, problem-based Teaching/Learning (Sharma \& Bansal, 2017).

Project-Based Learning is a "new method to learning that teaches a multiplicity of strategies needed for success in the twenty-first century," says O'Connor (2020).This form of training teaches students inquiry skills and how to work. Jigsaw is a popular collaborative/cooperative learning method that involves guided discovery teaching.

According to Kussmaul \& Pirmann, (2021), this teaching strategy is built on cooperative Learning and its underlying notions. This kind of instruction places students in groups and encourages them to work 
together throughout the teaching and learning process. According to Knapp (2019) what makes Jigsaw a successful teaching technique is that each student's success is crucial for the group's overall success. This stimulates teamwork and achievement.

\section{Role of instructors in the Social Constructivist}

Social constructivism validates instructional pedagogy by defining the teacher's function. This means teachers should use strategies that are:

In this approach, the students are the primary emphasis rather than the teacher.

\section{Learner-centred}

This means that students are encouraged to participate in their learning process more actively. You may allow them to generate their ideas, questions, definitions, and make-believe scenarios.

\section{Natural collaboration}

Here, the emphasis is on learning through social interaction rather than on individual effort. Specifically, students must work cooperatively to solve problems, analyses, and examine topics/situations to reach conclusions. It is through this process that students independently find or develop Knowledge.

\section{Instructor-guided Collaborative Learning}

Collaborative Learning occurs in social constructivist classrooms as a process of peer interaction supervised and structured by the teacher. Presentation of specific concepts, situations, or scenarios can catalyze discussion. The use of well-directed questions drives discussion, the introduction and clarification of ideas and information, as well as allusions to previously taught material (Kiraly,2014).

Sarita (2017) based on the above-mentioned strategies, the instructor is expected to:

- Create a social constructivist learning environment in the classroom that will encourage group engagement.

-To discourage competitiveness while encouraging collaboration and the sharing of experience among students, implement the following strategy: 
-Take the students' perspective or input into consideration, regardless of whether it is correct or incorrect.

-They provide students with the resources and advice they need to prompt them into knowledge construction in the path they wish.

-Assure that students are comfortable asking and answering questions, interacting with one another, and contributing to group discussions.

-Ensure that both more and less clever pupils benefit from their peers' experiences.

-Provide scaffolding support when and where required, at the appropriate time and the right level.

\section{Implications of social constructivism on learner}

Following are the implications of social constructivism on learners:

-Learners should discover lesson topics by responding to their instructor's encouragement as questions, tasks, assignments, projects, and other related activities instead of passively informing or loading them.

-Learners are now taught to collaborate and learn in groups formed by their instructor to achieve effective cooperative Learning.

-In sharing and building on their previous experiences, people become cocustodians of Knowledge, thereby fostering the creation of new information.

-Learners should accept responsibility for their Learning by active participation in cooperating learning activities

-The learner should learn to take into account the opinions of others by appreciating and studying fresh ideas and lessons learned from their peers and instructors.

-The learner should be willing to share their knowledge with their peers to enhance their cognitive abilities continuously. They should cherish each event and learn from them (McPhail,2016).

\section{Significance of social constructivism in Learning}

Knapp (2019) explain following ways of social constructivism that provide credibility to the learning environment:

-Social constructivism encourages learners to take an active role in the learning process. 
-It also encourages learners to participate actively and interact with instructors and other participants in the teaching-learning.

-Encourages kids to take the initiative and develop their ideas.

-Discourages students from engaging in rote learning or becoming passive in their studies.

-This increases curiosity while also assisting with retention.

-It helps to develop critical thinking and problem-solving skills.

-In the classroom, it encourages both individual and cooperative Learning.

-Because learners work in groups, it fosters a sense of camaraderie among them.

-By incorporating activity-based teaching approaches into the classroom, the instructor can arouse learners' natural curiosity.

-Encourages kids to have strong self-esteem due to their confidence in their ability to learn new things. The teacher supports the pupils in developing trust in themselves, believing in their abilities, and demonstrating that they can complete a given task.

-Encourages learners to investigate and interact with the available resources, which helps promote the active creation of Knowledge.

-Concretizes learning and Knowledge because learners are more likely to recall facts that they find and build on their own than data told to them or provided to them by the instructor.

-It aids in developing episodic memory, which refers to the ability to recall or reminisce about a prior event based on specific episodes or encounters around the occurrence. Kanno (2018) stated that these occurrences serve as benchmarks or memory reminders, which aid in retaining and recalling information, which is essential for effective Learning.

\section{Pedagogical principles of constructivism}

Van Hover \& Hicks (2017) have introduced the five following core principles of constructivism applicable in the classroom to foster a constructive learning environment.

-The first principle is to expose learners to new problems/situations. Focusing on students' interests and prior Knowledge helps them engage 
and become motivated to study. Questioning pupils' beliefs and ideas force them to reflect and consider.

-The learning process should be structured around fundamental concepts. Lessons should be planned around central concepts or ideas rather than isolated topics that may or may not be related. "Using broad concepts allows students of all styles, temperaments, and dispositions to participate."

-Constructivist teachers seek and value students' perspectives. This idea helps teachers access students' reasoning and thinking processes, further challenging them to make Learning relevant. Teachers should allow the students to share their thoughts and experiences and listen to them willingly.

-The fourth principle is to adapt the curriculum to deal with students' speculations. The functions of cognitive demands are implied in specific work (the curriculum) and rationale of the questions made by pupils involved in these activities (suppositions).

-Assessment of student learning in classroom instructions is the fifth principle that relates to the traditional divide between learning and evaluation environments. To accomplish authentic assessment, viewing significant student-teacher and student-student interactions.

These core principles have been offered to guide as overarching themes for teaching and learning environments consistent with constructivist experiences.

\section{Social constructivism in the classroom}

The following examples show how constructivist concepts are applied in the classroom:

- Constructivist concepts are used by teachers to encourage and accept the learners' self-sufficiency and innovation; constructivist principles inspire pupils to become more resourceful.

-Raw data and primary sources are incorporated by instructors into their lessons and planning, interactive, and substantial materials.

- Cognitive language is used by constructivist teachers when constructing assignments and responsibilities.

-Constructivist teachers allow students to shape class plans, adapt instructional tactics, and change content. 
-Before giving students more information about a subject, constructivist teachers inquire about the students' comprehension of the concept.

-Constructive learning environment encourages students' group work and interaction with teachers and peers as well. Moreover, constructivist teachers create opportunities for group discussion and active participation.

- Constructivist teachers encourage students to communicate, ask thoughtful, open-ended questions, and encounter difficulties and problems. In contrast, students may listen to the teachers and take notes in some classrooms; students are always encouraged to satisfy their queries to improve their Learning by constructivist teachers.

-Enquire about students' initial reactions is amplified by constructivist teachers in constructivist Learning. Insufficient Knowledge or incomplete Learning are obstacles. Thus, information is gathered about the early responses, and then elaborating these responses in the light of collected information is critical for improving Learning.

-Students are engaged in learning tasks to make concepts and information that may lead to discrepancies in their initial hypothesis, which they then use to convince conversation.

-Constructivist teachers usually allow extra time for students to study problems, seek solutions and explanations, and then respond. Teachers wait and maintain their patience as the pupil analyze the questions.

-Students are given time to form relationships and produce metaphors by constructivist teachers. It is critical to establish relationships and connections with both teachers and classmates in the classroom.

-Constructivist teachers cultivate students' expected inquisitiveness by frequently using the learning cycle process, which comprises the following three-stage learning cycle. This three-stage cycle of Learning focuses on meta-cognition. At the first stage, learners develop questions and hypotheses, i.e., when they are experimenting, the teacher broadens and focuses on the learners' point of view. Finally, there is a generalization, as students apply what they have learned. So, in this way, they can control and improve their Learning. They emphasize metacognition, students' Knowledge of their unique learning styles and approaches, and their strengths and shortcomings (Mishra 2014). 


\section{Conclusion}

However, social constructivist pedagogical ideas contradict traditional practices. To use these ideas, teachers must reflect on their work. Social constructivist teachers urge pupils to analyze their learning progress regularly. Moreover, social constructivist teaching promotes critical thinking and independent learners. In a social constructivist classroom, students should become experts. Student collaboration through participation in group activities is emphasized in social constructivism. In the perspective of social constructivism theory, meaningful Learning occurs due to social interaction, where learners interact for meaningful Learning. Teachers provide instructional assistance through teaching strategies that allow students to find and develop knowledge as they engage and collaborate throughout the learning process. Due to social constructivism, the role of learners has been changed from passive listeners to active participants and co-constructors of knowledge among co-learners, which also transfers responsibility of knowledge acquirement from the teachers to learners. 


\section{References}

1. Aljohani, M. (2017). Principles of "constructivism" in foreign language teaching. Journal of Literature and Art Studies, 7(1), 97-107.

2. Al-Qaysi, N., Mohamad-Nordin, N., \& Al-Emran, M. (2021). Developing an Educational Framework for Using WhatsApp Based on Social Constructivism Theory. In Recent Advances in Intelligent Systems and Smart Applications (pp. 243-252). Springer, Cham.

3. Amineh, R. J., \& Asl, H. D. (2015). Review of constructivism and social constructivism. Journal of Social Sciences, Literature and Languages, 1(1), 9-16.

4. Bybee, R. (2009). A commissioned paper prepared for a workshop on exploring the intersection of science education and the development of 21 st century skills. The BSCS 5E instructional model and 21st century skills..(RW Bybee, Ed.) USA: National Science Teachers Association. Pozyskane z: http://itsisu. concord. org/share/Bybee_21st_Century_ Paper. pdf [dostęp: 14.12. 2015].

5. Dorgu, T. E. (2015). Different teaching methods: a panacea for effective curriculum implementation in the classroom. International Journal of Secondary Education, 3(6), 77-87.

6. Fleury, S., \& Garrison, J. (2014). Toward a new philosophical anthropology of education: Fuller considerations of social constructivism. Interchange, 45(1-2), 19-41.

7. Jegede, S. A. (2010). Nigerian Students Perception of Technical Words in Senior Secondary School Chemistry Curriculum. Pakistan Journal of Social Sciences 7(2), 109-111.

8. Kanno, T. N. (2018). Guided discovery teaching method. In T. N. Kanno \& U. M. Nzewi (Eds.). Issues in Curriculum Development and Implementation in Nigeria. Lagos: Foremost Educational Services Ltd.

9. Kelly, J. (2012) Learning theories. Retrieved from http://thepeakperformancecenter.com/educationalearning/learning/theories/

10. Kennedy, J. (2014). Characteristics of massive open online courses (MOOCs): A research review, 2009-2012. Journal of Interactive Online Learning, 13(1).

11. Kiraly, D. (2014). A social constructivist approach to translator education: Empowerment from theory to practice. Routledge.

12. Knapp, N. F. (2019). The shape activity: Social constructivism in the psychology classroom. Teaching of Psychology, 46(1), 87-91.

13. Kussmaul, C., \& Pirmann, T. (2021). Guided Inquiry Learning with Technology: Investigations to Support Social Constructivism. In CSEDU (1) (pp. 483-490).

14. Kutay, C., Howard-Wagner, D., Riley, L., \& Mooney, J. (2012, September). Teaching culture as social constructivism. In International Conference on Web-Based Learning (pp. 61-68). Springer, Berlin, Heidelberg. 
15. Mathieson, S. (2012). Disciplinary cultures of teaching and learning as socially situated practice: Rethinking the space between social constructivism and epistemological essentialism from the South African experience. Higher Education, 63(5), 549-564.

16. McPhail, G. (2016). The fault lines of recontextualization: The limits of constructivism in Education. British Educational Research Journal, 42(2), 294-313.

17. Mishra, R. (2014). Social constructivism and teaching of social science. Journal of Social Studies Education Research, 5(2), 1-13.

18. Mohammed, S. H., \& Kinyo, L. (2020). The Role of Constructivism in the Enhancement of Social Studies Education. Journal of critical reviews, 7(7), 249-256.

19. Nawaz, A. (2012). Social-constructivism: Futuristic sphere for eLearning in HEIs. Global Journal of Management and Business Research, 12(8).

20. O'Connor, K. (2020). Constructivism, curriculum and the knowledge question: tensions and challenges for higher education. Studies in Higher Education, 1-11.

21. Olorode, J. J. \& Jimoh, A. G. (2016). Effectiveness of guided discovery learning strategy and gender sensitivity on students' academic achievement in financial accounting in Colleges of Education. International Journal of Academic Research in Education

$$
\begin{array}{lll}
\text { and Review. 4(6), pp. 182-189. } \\
\text { DOI:10.14662/IJARER2016.02. }
\end{array}
$$

22. Omotayo, S. A., \& Adeleke, J. O. (2017). The 5E Instructional Model: A Constructivist Approach for Enhancing Students' Learning Outcomes in Mathematics. Journal of the International Society for Teacher Education, 21(2), 15-26.

23. Omwirhiren,E. M. (2015). Enhancing academic achievement and retention in senior secondary school chemistry through discussion and lecture methods: a case study of some selected secondary schools in Gboko, Benue State, Nigeria. Journal of Education and Practice, 6(21), 155-161.

24. Rannikmäe, M., Holbrook, J., \& Soobard, R. (2020). Social Constructivism-Jerome Bruner. In Science Education in Theory and Practice (pp. 259-275). Springer, Cham.

25. Sarita, P. (2017). Constructivism: A new paradigm in teaching and learning. International Journal of Academic Research and Development, 2(4), 183-186.

26. Sharma, M. S., \& Bansal, D. (2017). Constructivism as paradigm for teaching and learning. International Journal of Physical Education, Sports and Health, 4(5), 209-212.

27. Singh, S., \& Yaduvanshi, S. (2015). Constructivism in science classroom: Why and how. International Journal of Scientific and Research Publications, 5(3), 1-5. 
28. Taylor, S. P. (2018). Critical realism vs social constructionism \& social constructivism: application to a social housing research study. International Journal of Sciences: Basic and Applied Research, 37(2), 216-222.

29. Van Hover, S., \& Hicks, D. (2017). Social constructivism and student learning in social studies. The Wiley handbook of social studies research, 270-318. 